organs; these are spoon-shaped, and are besides armed with horny processes, hooks, and other appendages, and must be looked upon as true generative organs. In the Astacida the sexual organs of the male are at the base of the first pair of abdominal legs, those of the female at the base of the third pair. Among the true winged-insects there is one remarkable case of abnormal position of these organs, in the dragon flies, which have the seminal vessels in the ninth, while the complex male sexual organs are situated in the second, abdominal segment. It is interesting to note that this curious anomaly occurs in an order which is considerea to be of the greatest antiquity and most generalised type among the true insects.

There are many other facts of a similar character to those I have now touched upon, and they all become clearly intelligible on the theory of Mr. Spencer, that the Annulosa are really compound animals, or, as he expresses it, "aggregates of the third order " while the other great groups of highly organised animals-Mollusca and Vertebrata-are typically simple animals, or "aggregates of the second order," (the cells of which their structures are built up being "aggregates of the first order"). Nothing of a similar character is to be found among the two latter groups. No molluscous or vertebrate animal can be divided transversely so that the separate segments shall be in any degree alike, and contain repetitions of any important organs. The distinct separation of parts in the vertebral column has been acquired, for it is less visible in the lower types than in the higher (the reverse of what obtains among insects), and in the lowest of ali is quite absent; while in none is there any corresponding multiplicity or displacement of respiratory, circulatory, or generative organs. The vertebral column corresponds rather to the segmenied shell of the Chiton, and has no more relation than it to the essential plan of the more important vital organs. Neither does any mollusk or vertebrate undergo spontaneous fission, nor that complete and progressive segmentation in the process of development which is characteristic of all Arnulosa ; nor do they ever exhibit the phenomena of parthenogenesis or alternation of generations, the essential feature of both which is, that numerous individuals are produced from a single fertilised ovum, by a process analogous to (or perhaps identical with) ordinary gemmation, and both which phenomena sometimes occur even among the higher insects.

In concluding this short sketch of a remarkable theory, I would observe, that if it is a true one it at once invests the objects of our study with a new and exceptional interest; because they are the most highly developed portion of a group of animals which will, in that case, differ fundamentally in their plan of structure from all other highly organised forms of life. In the study of the habits, instincts, and whole economy of insects, we shall have to keep ever in view the conception of a number of individualities fused into one, yet perhaps retaining some separateness of mental action, a conception which may throw light on many an obscure problem, and which will perhaps materially influence our ideas as to the nature of life itself. We must remember also, that if the insect is really a compound animal, then the only true homology that can exist between it and a vertebrate, or a mollusk, will be one between a single segment and an entire animal, and the search after any other will be so much lost time. Especially must the acceptance of this theory have an important bearing on all embryological and genetical studies ; and if the facts and arguments adduced by its learned and philosophical author do make out even a prima facie case in its favour, it must deserve the careful and unbiassed consideration of all who endeavour to solve the problem of the Origin of Insects.

\section{THE AUSTRALIAN ECLIPSE EXPEDITION}

$W E$ have already announced that no scientific results are to be expected from the Australian Eclipse Expedition, owing to the unpropitious state of the weather. The following particulars are obtained from the Melbourne Arous:-

"The five days intervening between the arrival at No. VI. Island and the eclipse were employed by the astronomical party in erecting and testing the instruments. Tents had to be put up, brick foundations and pedestals built, and distances determined. There was plenty of hard work, and the time at the disposal of the astronomers was found to be none too much. Nor were those who had to sleep on shore with the instruments to be envied. Possession of the island was hotly disputed by legions of rats, who behaved in the most impudent manner They boldly eyed the operations in the daytime, winking wickedly from behind the tufts of grass. Every night they held a corroboree in the tents, coursing over the instruments and the forms of the wearied sleepers, gnawing hats and any baggage which promised a toothsome morsel ; and in some instances they had the audacity to bite the men who attempted to brush them away. The passengers filled up the interval by visits to the mainland, and one or two of the neighbouring reefs and islets. On Thursday, December 8, Mr. Moore formed a party and went to Cape Sidmouth, the boat carrying provisions for three or four days. A native on the beach seemed much alarmed at their approach. When they landed he ran off at full speed and was not seen again. Only two other blackfellows showed themselves, though the tracks and camp fires proved that there were many in the neighbourhood. These blacks were known to be hostile, and it was necessary to take precautions to guard against a surprise. The master of the schooner Challenge, from Sydney, bound for Cape York, passed with his vessel a few yards astern of the Governor Blackall that morning. On hearing that a party had set out with the intention of landing at Cape Sidmouth, he expressed the consoling opinion that if they entered the bush they would never come out of it again. But no such disaster befel.

"On the hills, which rose abruptly a few hundred yards from the beach, were well-defined quartz reefs, and the neighbourhood presented all the appearance of auriferous country. A few miles from Cape Sidmouth was found an enormous heap of the bones of the dugong, the strange mammal which inhabits these seas. There were nearly two tons of bones, piled up in fantastic array, with all the skulls on top. At every turn were ant-hills, rising in solid cones from $6 \mathrm{ft}$. to $12 \mathrm{ft}$. high, and almost as hard as granite. Some of them had fine pinnacles, and these airy minarets, clustered together in graceful shapes, had a very pleasing effect. The numerous screw pines were also an agreeable feature in the landscape. The mountains, eight or ten miles inland, were well wooded, with occasional abrupt squares of grassed land.

"Mr. Moore prosecuted his botanical researches on the main. land during two days. Those who understand botany may be interested to learn from his account that the high ground at the cape is sparsely covered with stunted growths and trees, chiefly Eucaiypti and Grevillea chrysantha. Advancing into the interior, broad-leaved acacias and arborescent species of Hakea and Melaleuca principally characterise the open forest country. There are belts of thick jungle scrub of no great width, in which a very slender and graceful palm, which is believed to be new, occurs in great abundance. A species of Nepenthes, or pitcher plant, is also found in great profusion. Araliaceous trees are numerous. Ferns are scarce, but in the open forest the ground is thickly covered with Schizaa dichotoma. A very remarkable plant was found as an undergrowth in this, having large white bracts and bright green foliage. It is supposed to be a species of Mussanda. Toward the north of the cape is a long, low, flat country, chiefly covered with mangrove. The sandy patches contain a variety of undershrubs and climbers, with a tree here and there. The silk-cotton plant (Cochlospermum gossypium) also varies the scene with its delicate flower. Among these shrubs a very interesing plant-a species of Eugenia-was found. It bears a fruit about the size and colour of a cherry, having a pleasant sub-acid flavour. This fruit was largely eaten by the party, and the tree which bears it is supposed to be well worthy of cultivation. The vegetation is otherwise principally characterised by a species of Busbeckia, Elcodendron, Hibiscus, Bauhinia, and a species of Banksia. After leaving the mainland the party visited No. VII. Island of the Claremont group, where Mr. Brazier added an Auricula and a Bulimus to his previous collection of shells, which included specimens of the genera Diplommatina, Pupa, Halicarion, Helzx, Truncatella, Pythia, and Cassidula. Had the expedition selected a portion of the mainland for the observ. ing point, there would have been some interesting and extensive explorations in the interior. The party were fully equipped with arms and ammunition, some supplied by the Government and some privately owned, but with the ship nine miles off, and the limited time at our disposal, much exploration was impracticable. In any case, there was no anchorage for the vessel within two miles of the shore, and that was one of the reasons why the island was preferred for the observatory.

"On Thursday afternoon, some of the excursionists went in the captain's boat to look for shells on a small sandbank which had come into view, and landed on an island considerably smaller 
than the fish that Sindbad mistook for terra firma. It was intended to visit No. VII. Island, but it seemed that the country we were in search of had gone under water-its custom in the afternoon-and we sailed over part of it. On Friday a visit was paid to the reef, which extends for three or four miles from one extremity of No. VI. Island. The party landed on a patch of sand, and waded about three miles in 2 ft. of water over a coral bottom, in quest of shells. Here we had the wonders of the deep and its strange inhabitants laid at our feet in all their rich variety of colour. Some curious specimens were obtained. There were enormous clams, capable of holding a man's foot in their grip, abundance of bêche-le-mer, pearl oysters, all kinds of star fish (some of the most beautiful ultramarine), and many sorts of coral. One member of the party picked up a handsome live conch shell, weighing about $14 \mathrm{lb}$. Another was delighted with a strange creature belonging to the star fish order. When first taken from the water it had all the appearance of a pentagonal plum cake of about $2 \mathrm{lb}$. weight, beautifully encrusted with sugar crystals and profusely ornamented with coloured caraways. But removed from the sea water the glories of this appetising-looking creature only survived a brief period. When we had been a couple of hours prospecting on this rocky bottom of the ocean the tide rose rapidly, and we had no sooner got into the boat than the whole reef dropped out of view. The attractions of No. VI. Island proper were exhausted for the majority of people in a very brief space, but one or two were sometimes to be seen meandering along the beach, the very pictures of placid contentment. The presence of a porter bottle in one hand and an oyster knife in the other seemed to suggest that they had been visiting some of the oyster beds. They were so full of blessed condition that conversation was superfluous, and on these occasions we passed them without making a remark to disturb their dreamy hap. piness.

"Repeated attempts had been made since leaving Sydney to catch fish, but without success, only one small one having been hooked. This aiternoon, however, great sport was afforded by the sharks. The bathers who went over the ship's side every morning had been warned that there were several of these villanous footpads of the sea about; but nothing but the sight of these rapacious monsters on deck sufficed to induce them to abandon the practice. The method adopted in catching these sharks enabled both anglers and riflem $\pi n$ to take a part. As soon as a shark was hooked his head was drawn about six inches out of water, and three or four conical balls lodged in that ugly flat prominence settled him before he was hauled on deck to be drawn and quartered. In this way six, measuring frism oft. to I $2 \mathrm{ft}$. in length, were disposed of in the course of an hour and a half, besides two which were shot in the sea, and turned over on their backs to sink. After this experience the morning ablutions of the company were limited to splashing about the decks under the hose.

"Most of the company slept through the night on deck. With the marvels of the stellar firmament above, whichever way the eye was directed, we became contemplative astronomers, like the Chaldean shepherds of old. The striking garnitude of the sky formed an endless scene to gaze at and admire. Little wonder that the ancients made the heavenly bodies objects of religious veneration. When the sun had finished his daily round, we watched the lesser light that rules the night, making her stately procession through the heavens, and the infinite variety of stars moving in concert through boundless space. There is much of the charm of romance in the study of the science which teaches us that there are other globes, in comparison with which the earth is but a speck, and proves to us that the 'patines of bright gold ' with which the sky is inlaid are not simply points of light, but worlds like our own, with systems of satellites moving in their appointed courses in obedience to the laws of nature. These unknown countries afford abuxdant scope for interesting speculation. The mind endeavours to picture the circumstances of their inhabitants, and to conjecture, by some earthly standard, what their pursuits may be. But the imagination refuses to believe that the occupants of these bright worlds are subject to the conditions which bind those who dwell upon 'the dim spot which men call earth,' and that they have cities like ours, with their sins and their sorrows. There were some stars in the firmament which old residents of Australia had not seen for many years. While our vessil was progressing norbwards, constellations unknown in the south had heen comirs into view, and we saw Cassiopeia and Perseus gradually rise above the horizon with great brilliancy. Apart from the scenery of the heavens, the sea was beautifully phosphorescent. When the phosphorescence was stirred all the sparks were converted by the action of the retina into lines of light, which played around the ship in radial streamers.

"No time was lost by the astronomical party when they liad once effected a landing on Eclipse InIand, as we christened the point of observation. The islet was soon converted into a bustling little canvas town. From nearly every tent some instrument peered, all pointing in the one direction, as though these mortals, with their puny optics, thought to stare out of countenance the great Eye of Day. The Victorian party had two analysing spectroscopes and an integrating spectroscope, both equatorially mounted. The first was in the hands of Mr. Ellery, and the second was to be worked by Mr. Foord, both gentlemen having assistants to use the finding telescopes attached to pick out portions of the corona for examination. The two analysing spectroscopes were for examining the nature of the light of the chromosphere and the corona ; and the integrating spectroscope, entrusted to $\mathrm{Mr}$. $M$ 'George, was designed to examine the na'ure of the whole light, all the observations being directed with a view to determining the character of the orb from which the light proceeds. Prof Wilson had two Savart's polariscopes. The object of polariscopic observations is to ascertain whether the light of the corona is that of a self-luminous body or a reflected light; also, in the case of its being a reflected light, to determine the angle of incidence, the great question to be settled being whether the corona is an appendage of the sun, or whether it exists in our atmosphere. There was also a magnetic theodolite to record magnetic disturbances. Mr. Moerlin, assisted by Mr. Walter, had charge of the photographic department. The principal instrument was one of Dalmeyer's rapid rectilinear lenses of 4in. aperture and 3 oin. focal length, giving an image of about threetenths of an inch in diameter, equatorially mounted, and driven by cluckwork. It was intended to take ten view's during the totality. Mr. White, assisted by Mr. Black, directed the instruments for determining the position of the station and predicting the time of the different phases of the eclipse. On the morning of the $7^{\text {th }}$ December a brick pier to support the transit instruments was built. The pier was made square, as the instruments had to be placed not only in the meridian for the accurate determination of the time and longitude, but also at right angles to the meridian for finding the altitude. The first observations were made by an eight-inch altazimuth, which dues not require such a massive stand as the transit. This gave very nearly the local time and the direction of the meridian. By means of these data the transit was fixed at right angles to the meridian, the finding of the laritude by this method being more troublesome and requiring finer weather than the finding of the time. On the first night the sky was rather cloudy, so that only two comp!ete ob. servations could be taken. The next night three observations were obtained, and the third night four observations were made This being considered sufficient for the latitude, the instrument was next morning placed in the meridian, but the weather was so unfavourable tnat no observations could be taken in that posi. tion, so that the altazimuth had to be resorted to for the time observations.

"The Sydney party were furnished with an equatorial tele. scope, made by Merz, of Munich, with $7 \frac{1}{4}$ in. clear aperture and roft. $4 \mathrm{in}$. focal length, mounted on the German plan. Attached to the telescope was an apparatus for taking pho:ographs in the principal focus of the object glass; also a photographic lens and camera, by which a second series of photographs could be taken simultaneously, the photograph c lens having a 3 in. aperture and 3oin. focal length. There were, in addition, two small telescopes of $2 \mathrm{in}$. aperture, with a maynifying power of 20 , mounted equatorially and driven by clockwork, and a third telescope of $3 \frac{1}{\mathrm{i}} \mathrm{in}$. aperture and $4 \mathrm{ft}$. $6 \mathrm{in}$. focal length. The party intended to take a duuble series of photographs, to make two independent drawings, and to make naked-eye drawings and observations. The duties were apportioned as follows:-Mr. Russell, the Government astronomer, was to take photographs with the large telescope; Mr. Beaufoy Merlin photographs with the camera, the Rev. W. Scott and Lieutenant Gowlland to make drawings with small telescope, and $\mathrm{Mr}$. W. M'Donnell to act as timekeeper. The passengers were furnished wirh diagrams, and each received instruciions to pay special attention to some one particular portion of the phenomena. When the day of the eclipse arrived the instruments were all working admirably. There had been numerous rehearsals to secure the utmost economy of time, and all felt that nothing but clear weather was needed for success. 
"On Monday afternoon, the I Ith of December, for the first time since leaving Melbourne, the sky became seriously overcast. The clouds had been gathered in dense dark masses all the earlier part of the evening, and at ten o'clock at night there was an awful thunderstorm, which lasted over an hour. The glow of the lightning, which came down in sheets of flame, and the rattle and crash of the thunder which followed the flash instantly, were inexpressibly grand. It was something quite beyond the experience of any one on board. A portion of the astronomical party returned from the shore in the middle of the storm. While they were ascending the ship's side the lightning struck the iron rigging, leaped across from stanchion to stanchion in balls of fire, and broke off at the ropes depending from the dead-eyes with loud crackling noises before it reached the sea. The vessel was lit up from stem to stern with a blinding light, and those on deck could see nothing for some seconds after each fiash. The party in the boat were so much affected in this way that some alarm prevailed at first. Each one thought he had been deprived of sight, and asked his neighbour how it was with him. Had we been in a wooden ship the consequences would in all probability have been serious. This storm unfortunately did not clear the atmosphere. Next morning, the day of the eclipse, every eye was turned heavenward. To our dismay there was not a speck of sky to be seen. At ten o'clock there were several breaks in the clouds, and the sun showed himself for a few seconds, but an hour and a half later all was densecloud again. Things looked brightest at mid-day, when there seemed to be a possibility of a fine afternoon. Then dark clouds swept up from the horizon, and extinguished almost every hope. At two o'clock there was yet another chance, though a faint one. This was tantalising. Every in. terest centred in a few patches of sky and their relations to the neighbouring clouds. They were aggravating clouds of every imaginable form and variety - cirrus, stratus, cumulus, nimbusall were there at various times of the day, assuming the most distressing shapes, but giving no promise of dissolving.

"The computation of the duration of the eclipse was found to be very accurate, the eclipse occurring, as near as could be judged, three or four seconds before the predicted time. The computation was as follows:-First contact, $1 \mathrm{~h}$. $15 \mathrm{~m} .6 \mathrm{~s}$. ; commencement of totality, 2h. 42m. 23s. ; end of totality, 2h. $45 \mathrm{~m} .49 \%$; last contact, $4 \mathrm{~h}$. $\mathrm{Im}$. $6 \mathrm{~s}$. At the time of the first contact there was scarcely a rift in the canopy of clouds. The sun was wholly obscured. A few seconds later a passing glimpse was obtained, showing that the encroachment of the dark body of the moon on the bottom edge of the sun's disc had begun. Then all was dark again, excepting a faint luminous spot indicating the radiant body's position. A sharp shower fell at this time, and the instruments exposed had to be covered up. A drizzling rain continued during the remainder of the afternoon. At the faintest indication of a break in the clouds the astronomers ran out of their tents, and endeavoured to take observations, but without any result. Seven minutes before the commencement of totality there was a gleam of light from the sun, but the phase of the eclipse could not be discerned. We caught a momentary glimpse of the silver sickle of the sun at the top, just before the full obscuration. Then darkness fell suddenly like a pall on the surrounding objects, and we knew that totality had begun. It was a strange weird light at first. The large billowy clouds assumed olive and purple tints, and then changed to an ashen hue. These colours were refiected in the sea with some variations of light green and copper. Men looked livid in the light, and everything around had a most unearthly appearance. The steamer at anchor showed with a wonderful distinctness; every line, spar, and bit of cordage stood out against the horizon with the sharpness of a highly-magnified stereoscopic picture. There was no total darkness, owing, probably, to the amount of light diffused in the clouds. During totality, newspaper print could be read without much difficulty. Nor was there any perceptible diminution in the temperature. The three minutes and a half seemed exceedingly short. We saw nothing of the corona beyond a brief glimpse of a luminous mark shining faintly through the vapours. Some said they detected a decided red tinge. The clouds turned black, the tints disappeared from the sea, and utter darkness seemed coming upon us, when a few rays of light played upon the edges of a great bank of clouds in the N.W., some of the grey tints of dawn appeared, and daylight came back with a rush, as from the lifting of a veil. A hawk which had been sailing about swept down into a bush on the island to roost as soon as totality began. When daylight returned, he was astonished to find himself within a few feet of forty or fifty men, and flew off in wild alarm. Though daylight had returned, the sun was still hidden by the clouds. A minute later we faintly saw the re-appearance of the solar $\operatorname{limb}$ at the bottom like a fine luminous thread, when more clouds interposed and shut out the great luminary for the remainder of the afternoon. This was all that was vouchsafed to us of the grand phenomena of a total solar eclipse. Never was Nature more assiduously wooed to reveal her treasures to science. But it was all to no purpose. Of the upward and onward march of the moon, the successive disappearance of the solar spots, the brilliant breaking into view of Bailey's Beads, the passage of the shadow through the air, the rose-coloured prominences and coronal radiations during totality, the reappearance of the solar crescent, and the final retreat of the lunar shadow into space, we had seen nothing. No observation could be taken by instrument. Mr. Russell exposed a photographic plate for twenty seconds during totality, but got no result.

"Nothing remained but to pack up and head the ship for home. The work was commenced before the eclipse was over, the rain falling dismally all the time, and was completed in less than three hours. The disappointment to all was very great. It was especially felt by the astronomical party, but they bore it bravely, as became men who had faithfully performed their duty. When over dessert that evening Mr. Ellery proposed in the interests of science, "Success to the Other Eclipse Expeditions," there was not one who did not cordially wish that all the other observers might have presented to their view the radiant globe projected on an azure sky, instead of the mountains of dull cloud that desolated our hopes.

"Later in the evening the schooner Matilda, bound for Sydney, from Torres Strait, with twelve tons of pearl shell, came alongside. The master and first officer reported having seen the eclipse very distinctly while near Night Island, in lat. $13^{\circ} 9^{\prime} \mathrm{S}$., long. $143^{\circ} 39^{\prime} \mathrm{E}$., about 15 miles from No. VI, island. They were not aware that the eclipse was going to occur, and at first took the darkness for approaching bad weather, until one of them happening to look under the mainsail, observed the phenomenon. Though wholly unprepared for the eclipse, they gave a very intelligent account of it, on being carefully examined by Prof. Wilson. Mr. Walton, master of the Matilda, stated that he had just ordered some clothes that were drying to be taken down, as bad weather seemed to be coming on, when he happened to look up and see the eclipse. It was so dark that he had to light the binnacle lamp. On a diagram being handed to him, he correctly indicated the points of disappearance and first reappearance of the sun. He drew on a black disc a line showing the boundary of the ring of light round the dark body of the moon, narrower in the right-hand bottom quadrant, and wider, with a projection, in the left-hand top quadrant. The colour of the light, he said, was whitish, like ordinary sunlight. $\mathrm{He}$ was particularly asked if he saw any pink light, and said no. He described the boundary as being sharp, and clear towards the moon, but rough and irregular outwards. The breadth of the annulus which he drew was about I-16th of the diameter of the black disc. He said he and the other officers differed as to the duration of the darkness. The time was variously guessed at from five to ten minutes. His own opinion was that it was seven or eight minutes. There were no clouds on the sun at the time, and the blue sky was visible. Some of the South Sea Islanders on board were very much alarmed, and wept plenteously. Mr. Hore, first officer of the Matilda, stated that on his attention being directed to the eclipse, he went below to fetch his sextant in order to use the dark glasses. The captain called to him to make haste, as he was losing the best of it. On coming on deck he saw the dark body of the moon, surrounded by a fine ring of red light, outside of which was a broader ring of paler red light; while all outside of that was as black as night. His drawing on the card showed the breadth of the inner ring to be one-eighth the diameter of the moon, and the breadth of the outer on to be seven-sixteenths of the diameter of the moon. On being pressed as to the colour, he said it was not. like fire itself, but like the glow of fire when the fire is concealed. The illustration he used was the glow of a house on fire seen from behind another house. Only one cloud passed over the sun during the eclipse, and that was a very small one. Peter $R$. Cooper, carpenter on board the Matilda, drew a line showing the boundaries of the inner and outer annuli, the inner one extending rather more than half round, the point of first reappearance being the middle of it, the outer one extending less than a 
quadrant, and being entirely on the upper right-hand side. He described the colour as being like the upper ground part of a kerosene lamp shade in the cabin to which he pointed. The sun looked watery. When he first saw it it was coming from behind scud. There was no sky which could be called blue. It was a whitey sky. Cooper's drawing was marked' with radial lines extending across the outer annulus from the inner.

"The return voyage was begun at daylight on the morning of the $13^{\text {th }}$ of December. The only lasting traces of the astronomers left on the island were the photographers' dark rooms and the brick foundations used for the instruments, in which were entombed two bottles containing coins and newspapers and some particulars of the expedition. A member of the party, animated by something of the spirit of Old Mortality in his desire to preserve from oblivion the mortuary memorials of the expedition, inscribed this touching record on the slab which formed the top of one of these pedestals :--' Sacred to the memory of the Australian Eclipse Expedition." "

\section{SOCIETIES AND ACADEMIES}

LONDON

Royal Society, February 15.-- "On the Irduction of Electric Currents in an infinite plane sheet of uniformly conducting matter," by Prof. Clerk Maxwell; F. R.S.

The currents are supposed to be induced in the sheet by the variation in position or intensity of any system of magnets or electromagnets.

When any system of currents is excited in the sheet, and then left to itself, it gradually decays, on account of the resistance of the sheet. At any point on the positive side of the sheet, the electromagnetic action is precisely the same as if the sheet, with its currents, retaining their original intensity, had been carried away in the negative direction with a constant velocity $R$, where $R$ is the value, in electromagnetic measure, of the resistance of a rectangular portion of the sheet, of length $I$ and breadth $2 \pi$. This velocity, for a sheet of copper of best quality of one millimetre thickness, is about twenty-five metres per second, and is, therefore, in general comparable with the velocities attainable in experiments with rotating apparatus.

When an electromagnet is suddenly excited on the positive side of the sheet, a system of currents is induced in the sheet, the effect of which on any point on the negative side is, at the first instant, such as exactly to neutralise the effect of the magnet itself. The effect of the decay of this system of currents is therefore equivalent to that of an image of the magnet, equal and opposite to the real magnet, from the position of the real magnet, in the direction of the normal drawn away from the sheet, with the constant velocity $R$.

When any change occurs in an electromagnetic system, whether by its motion or by the variation of its intensity, we may conceive the change to take place by the superposition of an imaginary system upon the original system; the imaginary system being equivalent to the difference between the original and the final state of the system.

The currents excited in the sheet by this change will gradually decay, and their effect will be equivalent to that of the imaginary system carried away from the sheet with the constant velocity $R$.

When a magnet or electro-magnet moves or varies in any continuous manner, a succession of imaginary magnetic systems like those already described is formed, and each, as it is formed, begins to move away from the sheet with the constant velocity $R$. In this way a train or trail of images, is formed, moves off, parallel to itself, away from the sheet, as the smoke of a steamer ascends in still air from the moving funnel.

When the sheet itself is in motion, the currents, relatively to the sheet, are the same as if the sheet had been at rest, and the magnets had moved with the same relative velocity. The only difference is, that whereas when the sheet is at rest no difference of electric potential is produced in different parts of the sheet, differences of potential, which may be detected by fixed electrodes are produced in the moving sheet.

The problem of Arago's whirling disc has been investigated by MM. Felici and Jochmann. Neither of these writers, however, has solved the problem so as to take into account the mutual induction of the currents in the disc. This is the principal step made in this paper, and it is expressed in terms of the theory of images, by which Sir W. Thomson solved so many problems in Statical Electricity. In the case of the whirling disc, the trail of images has the form of a helix, moving away from the disc with velocity $R$, while it revolves about the axis along with the disc. Besides the dragging action which the disc exerts on the magnetic pole in the tangential direction, parallel to the motion of the disc, the theory also indicates a repulsive action directed away from the disc, and an attraction towards the axis of the disc, provided the pole is not placed very near the edge of the disc, a case not included in the investigation. These phenomena were observed experimentally by Arago, Ans. de Chimie, 1826.

February 22.-“"On a New Hygrometer." By Mr. Wildman O. Whitehouse.

"On the Contact of Surfaces." By William Spottiswoode, M.A., Treas. R.S.

In a paper published in the "Philosophical Transactions" (1870, p. 289), I have considered the contact, at a point $P$, of two curves which are co-planar sections of two surfaces $(U, V)$; and have examined somewhat in detail the case where one of the curves, viz., the section of $\mathrm{V}$, is a conic. In the method there employed, the conditions that the point $\mathrm{P}$ should be sextatic, involved the azimuth of the plane of section measured about an axis passing through $\mathrm{P}$; and consequently, regarded as an equation in the azimuth, it showed that the point would be sextatic for certain definite sections. It does not, however, follow, if conics having six-pointic contact with the surface $U$ be drawn in the planes so determined, that a single quadric surfaee can be made to pass through them all. The investigation therefore of the memoir above quoted was not directly concerned with the contact of surfaces, although it may be considered as dealing with a problem intermediate to the contact of plane curves and that of surfaces.

In the present investigation I have considered a point $\mathrm{P}$ com. mon to the two surfaces, $U$ and $\mathrm{V}$; an axis drawn arbitrarily through $\mathrm{P}$; and a plane of section passing through the axis and capable of revolution about it. Proceeding as in the former memoir, and forming the equations for contact of various de. grees, and finally by rendering them independent of the azimuth, we obtain the conditions for contact for all positions of the cutting plane about the axis. Such contact is called circumaxal ; and in particular it is called uniaxal, biaxal, \&c., according as it subsists for one, two, \&c. axes. If it holds for all axes through the point it is called superficial contact; and in the memoir some theorems are established relating to the number of sections along which contact of a given degree must subsist in order to ensure uniaxal contact, as well as to the connection between uniaxal and multiaxal contact. At the conclusion of sec. 3 it is shown that the method of plane sections may, in the cases possessing most interest and importance, be replaced by the more general method of curved sections.

In the concluding section a few general considerations are given relating to the determination of surfaces having superficial contact of various degrees with given surfaces; and at the same time have indicated how very much the general theory is affected by the particular circumstances of each case. The question of a quadric having four-pointic superficial contact with a given surface is considered more in detail ; and it is shown how in general such a quadric degenerates into the tangent plane taken twice. To this there is an apparently exceptional case, the condition for which is given and reduced to a comparatively simple form; but I must admit to having so left it, in the hope of giving a fuller discussion of it on a future occasion.

The subject of three-pointic superficial contact was considered by Dupin, "Développements de Géométrie," p. 12, and, as I have learnt since the memoir was written, a general theorem connecting superficial contact and contact along vario:s branches of the curve of intersection of two surfaces (substantially the same as that given in the text) was enunciated by M. Moutard *

In a corollary to this theorem, M. Moutard states that through every point of a surface there can be drawn twenty-seven conics, having six-pointic contact with the surface. This number is perhaps open to question; and I have even reason to think, from considerations stated to me by Mr. Clifford, that the number ten, given in my memoir above quoted, may be capable of reduction by unity to nine. But this question refers to the subject of that earlier memoir rather than to this.

Geological Society, February 7.--Mr. Prestwich, F.R.S., president, in the chair. I. "Further Notes on the Geology of the neighbourhood of Malaga," by M. D. M. d'Orueta. In this paper, which is a continuation of a former note laid

* Poncelet, "Applications d'Analyse à la Géométrie," x864, tom. ii. p. 363 